\title{
The Evolutionary Approach to Political Psychology
}

\author{
Michael Bang Petersen \\ Department of Political Science \\ Aarhus University \\ michael@ps.au.dk
}

Chapter prepared for the Oxford Handbook of Political Psychology. 
Why do you eat? This may seem like a simple question. But there are in fact multiple different ways of answering this question correctly. One immediate - and correct - way of answering this question is to say, "I eat because I am hungry." But another equally correct way of answering this question is to say, "I eat to acquire necessary nutrients and energy." The first answer describes how the phenomenon of eating appears to our own conscious senses: I feel hunger and then I go to the fridge to get some food. The second answer describes the function of that phenomenon: the reason why we have a sense of hunger and why we are so motivated to act on it. Note that this second form of answer or explanation may in itself help us flesh out the first answer in more detail. Knowing that we eat to acquire energy and nutrients may help us predict, for example, which kinds of foods we find particularly delicious.

Evolutionary approaches to political psychology apply this second form of explanation to the domain of politics, focusing on the potential functions of the psychological mechanisms that guide political decisions and behaviors. Such mechanisms are instantiated in the human and must therefore have a biological basis. Within biology, there is only one explanation of the existence of functionality: Darwin's theory of evolution by natural selection. Why and how to theorize about political psychology using evolutionary theory - and what are the implications for discussions within the field of political psychology - is the topic of this chapter.

It may seem strange to propose that biological evolution - and, hence, the deep prehistoric past of humans - has any relevance for political psychology. Afterall, is there anything more modern, technical, and complex than politics? Yet, the core argument of this chapter is that underneath this complexity is a number of fundamental problems of social life that we, as a species, have been recurrently facing for thousands and thousands of years. If evolution had not designed us to deal with these problems, we would not be here today and, accordingly, we should expect the human mind to contain a large number of psychological mechanisms specifically dedicated to 
political decision-making. While much research in political psychology laments the political sophistication of the average citizen, evolutionary approaches in contrast highlight the opposite. As will also be clear, however, our political nature was designed to solve problems in the particular environments of the ancestral past and, hence, will fail in predictable ways when applied to the problems that are unique to the politics of modern mass societies

The chapter will review core concepts from evolutionary biology and the field of evolutionary psychology, which was specifically invented to bridge the natural and social sciences (Buss, 2019). The evolutionary approaches reviewed here are thus applications of the wider field of evolutionary psychology to political psychology. The chapter then applies these outlined concepts to political psychology and provides a number of illustrations from recent research using an evolutionary approach. Finally, the chapter ends with trying to clear up a number misunderstandings about evolutionary political psychology, which are widespread or may occur during the reading of the chapter. Thus, the reader should be warned that some of the conceptual framework is rather complex (and cannot be given full justice here) and will clash with a number of intuitions about how people make decisions. At the same time, however, the overall message of the chapter can be phrased in simple terms: Just as fish are designed by natural selection to navigate through water, humans are designed to navigate swiftly and effectively through the political problems that pervaded the lives of previous generations. The implications of this message, however, are wide-ranging.

\section{Asking Evolutionary Questions}

To understand both the conduct and the goals of an evolutionary approach to political psychology, some rudimentary vocabulary from evolutionary biology is required. While a full treatment is far beyond the scope of this chapter, it will briefly introduce two important distinctions. The first is the distinction between ultimate and proximate explanations. The second is the distinction between 
adaptations and by-products. The first distinction highlights the categories of questions pursued by evolutionary biologists - and, by extension evolutionary political psychologists - and the second distinction highlights the categories of answers they provide.

Evolutionary biologists distinguish between, at least, two types of explanations: One is called ultimate or functional explanations. The other is called proximate or mechanistic explanations. As carefully laid out in introductions to these different explanations there is no rivalry between these two types (Scott-Phillips et al., 2011). They are fully complementary and seek to accomplish two different but equally valuable things.

Proximate explanations are explanations that traditional political psychology often revolve around. These explanations often proceed questions of how? How do partisan social identities influence political participation? How is anger triggered in the context of political discussions? How do stereotypes about welfare recipients influence support for the welfare state? These explanations involve descriptions of the psychological mechanisms responsible for producing political motivations and behavior. In the introductory example of eating, the explanation "I eat because I am hungry" is an example of a proximate explanation that highlights the proximate motivations involved in the production of a behavior.

Evolutionary political psychology is unique in making active use of ultimate or functional explanations. Ultimate explanations are explanations that are often proceeded by questions of why? In the introductory example of eating, the ultimate explanation is that eating provides essential nutrients and calories for developing, sustaining, and propelling the organism. This is the function of eating. In political psychology the questions that would invite ultimate explanations would be questions like the following: Why do people form strong political identities? Why do people become angry with lazy welfare recipients? Why are people prejudiced towards people of another race or ethnicity? 
In evolutionary biology there is only one explanation for the existence of functional processes ingrained in our biology: Adaptation via natural selection. Natural selection is, in short, the cumulative effect of the environment over generations on the differential reproduction of genes that mutate randomly. To elaborate, organisms are composed of genes and genes build these organisms and, hence, influence the way organisms interact with the environment in which they are localized. Organisms reproduce and, in the reproduction process, some genes will randomly mutate. Some mutations will make the next generation of organisms slightly better adapted to their environment in the specific sense that this next generation will leave relatively more offspring in this environment. Some other mutations will make the next generation slightly less adapted. The environments provide what is called a selection pressure. Over generations the differential reproduction rates created by this pressure will imply that better adapted genetic designs accumulate (i.e., are being selected) and spread in the gene pool that defines a species. They become species-typical adaptations.

Some of these adaptations will be physical in nature. The heart, for example, is a physical adaptation evolved specifically to circulate blood and, hence, serves the function of bringing oxygen and nutrients to all parts of the body. The eyes are another physical adaptation that functions as an interface that allows the organism to process and react to distal objects by catching the light they transmit and turning these light signals into nerve signals that can be transmitted within the organism. The eyes also serve as an example of how adaptations can serve psychological and not just physical functions (Tooby \& Cosmides, 1990). Essentially, the eyes serve the psychological function of building the basis for the mental imagery that serves essential roles in decision-making.

Human life is filled with choices. Some of the choices you make will harm you. Some of the choices will benefit you. Accordingly, an extraordinary number of adaptations exist with the exclusive purpose of aiding decision-making. While such a claim might have been controversial a few decades ago, the evidence for the psychology influence of genes is now so powerful that the 
claim is almost trivial but important nonetheless (Penke et al., 2007). What may still be controversial, however, is the claim that some of these psychological adaptations evolved specifically to aid political judgment and behavior.

The genes underlying any adaptation - whether physical or psychological - spread because that adaptation helped generations of organisms solve a specific problem. Such problems are referred to as adaptive problems (Tooby \& Cosmides, 1992). As with any other efficient problemsolving device, adaptations are problem-specific. Think of the craftsman's toolbox. There is a dedicated tool for hammering in nails, a dedicated tool for putting in screws, and a dedicated tool for sawing wood. The demands of the problem dictate the features of the tool. In Denmark, where I am living, there was once a long-running TV quiz show where two teams were presented with an old and often quite obscure - tool. By examining the features of the tool, they tried to predict what it was for. And because of the match between form and function, the teams were surprisingly good at making educated guesses.

The predictable match between form and function lies at the heart of the methodological approach of evolutionary psychologists when they derive ultimate explanations. Thus, by examining the features of an adaptation, it is possible to build educated and testable hypotheses about the adaptative problems that an adaptation evolved to solve. Furthermore, the connection between form and function is a methodological two-way street. Evolutionary psychologists do not just predict function from form. They also predict form from function. That is, by examining the specific demands of an adaptive problem in the evolutionary past of a species it is possible to build predictions about the current structure of the specific adaptation that evolved to solve that problem. Thus, by examining the adaptive problems of politics in ancestral life, an evolutionary approach entails developing testable hypotheses about the structure of political psychology. 
Adaptations are functional. Adaptations, however, are not the only product of biological evolution; evolutionary psychologists are also oriented towards another product: by-products. Byproducts are, as indicated by the term, features that are produced by adaptations but are not in themselves adaptations. An example is the color of bones. There is no inherent functionality to the white color of bones. They could fulfil their function as easily being red, blue, or purple. But given that bones are built of calcium, they just happen to be white. The color is a by-product. Evolutionary psychologists sometimes use by-products in two slightly different senses. One is in the strict sense that the feature has no functional purpose whatsoever. The white color of bone is one such example. Another is in the sense that the feature of an evolved decision-making mechanism is adapted for a different purpose than how it is currently utilized (sometimes referred to as being caused by a "mismatch" between current and ancestral environments; we return to this later). One example is the tendency to pay attention to the race of others, which is arguably not an adaptation in itself but reflects the structure of decision-making mechanisms for detecting alliances (Kurzban et al., 2001). Another example is disgust reactions to people with another skin color, which may reflect the structure of decision-making mechanisms for using physical deviations from a psychological prototype as indicators of infection (Petersen, 2017). Despite the acknowledgement of other products of evolution, evolutionary psychologists often focus on adaptations because evolutionary biology provides the tools for developing hypotheses about adaptations: functional analyses of the demands posed by specific adaptive problems.

\section{How To Derive Hypotheses Using Evolutionary Psychology?}

The philosopher of science, Karl Popper, argued that there are no rules for theorizing, only for testing your theories. Hypothesis formation entails a "creative intuition" or an "irrational element" in his view (Popper, 2005 [1959]). Yet, evolutionary psychology offers exactly a toolbox for theorizing: a 
set of principles, grounded in one of the best validated scientific frameworks, for deriving testable predictions about the structure of psychological mechanisms.

Methodologically, evolutionary psychologists derive these predictions by relying on the relationship between the form of psychological mechanisms and their function. One method (sometimes referred to as reverse engineering, Tooby \& Cosmides, 1992) entails building predictions about the function of a mechanisms by knowing their structure. Another method (sometimes referred to as forward engineering, Nairne, 2015) entails building predictions about the structure of mechanisms from their presumed function. Most often, however, the concrete research process entails going back and forth between these methods of inquiry. First, a function is often proposed by examining what is known about a psychological mechanism in the existing literature (reverse engineering) and, second, predictions about previously unknown features of the psychological mechanisms are then derived on the basis of this function (forward engineering). After deriving the predictions, doing research is business as usual: Run empirical studies to test whether the mechanisms operate as predicted.

The core purpose of much evolutionary psychology is thus to validate and uncover the proximate structure of relevant mechanisms. Importantly, this structure is also the only explanation being supported by the empirical tests. Empirical confirmation of the hypotheses does not prove the ultimate explanation used to generate the proximate predictions. The primary purpose of the ultimate explanations is to assist us in making better predictions. When used in this way, evolutionary political psychology conforms to the views about science formulated by another key philosopher of science (and student of Popper), Imre Lakatos: Research programs contain a set of a "hard core" of assumptions that are never put directly to test; they are only tested in combination with further auxiliary assumptions that generate the direct observable implications (Lakatos, 1976). While the ultimate explanations constitute such a "hard core" in much evolutionary political psychology 
research, this does not mean that they are not put to test by anyone. In fact, testing the core principles - the logic of evolution, the nature of adaptions, the history of human evolution, and so forth - is exactly the business of other, more fundamental disciplines in the hierarchy of the sciences. What constitutes assumptions for the psychologist and social scientist are the direct objects of empirical investigation for the biologist.

\section{Why Are Ultimate Explanations Relevant for Political Psychologists?}

It is tough job to raise and answer questions about ultimate explanations. So, why should you as a political psychologist nonetheless try? In addition to the argument in the preceding section that evolutionary psychology helps researchers theorize about the structure of psychological mechanisms, there are, at least, two other reasons why an evolutionary approach to political psychology can be worthwhile.

\section{Generating a more complete understanding}

The first reason is that pursuing ultimate explanations provides a more complete understanding of the world we are living within. That is, after all, the business of all science - to pursue explanations even when (or exactly because) it is difficult. In fact, the viewpoint from an evolutionary approach, which is likely to be controversial among many political psychologists, is that this is the only way to actually explain behavior. In traditional political psychology, questions of why are also routinely raised and answered but often the explanations provided are proximate explanations disguised as ultimate explanations. For example, social identity theorists often argue that people seek strong social identities to manage self-esteem (Rubin \& Hewstone, 1998). And it is certainly true that the mechanisms that regulate the acquisition of social identities produce self-esteem as an output when the individual is part of a high-status social group. But this is not an ultimate explanation. Ultimate 
explanations are functional explanations that require a feedback mechanism whereby the functional behavior creates the machinery that produces the behavior. Evolution does not care about your feelings including your self-esteem. No matter how good a certain kind of behavior makes your feel, this does not make that behavior more likely to become fixed in the pool of genes that makes up our species' nature. Still, making and testing ultimate predictions about how, when, and why certain social behaviors evolved are extremely difficult. The good news is that most often the most difficult parts are of less relevance to the political psychologist. Whether the adaptations underlying a particular behavior evolved 100,000 years ago or 250,000 years ago is often of little importance for their purposes.

\section{Consilience as a solution to the replication crisis}

Evolutionary psychology is first and foremost a bridge - a set of principles that connects the natural and the social sciences by using assumptions verified by natural science to build predictions on human psychology and therefore ultimately all human behavior. The view of science as a unified enterprise with a clear division of labor as well as a clear hierarchy (starting with physics then chemistry, biology, psychology and, finally, the social sciences) is sometimes referred to as consilience (Wilson, 2000). At the simplest level, the conduct of evolutionary political psychology is nothing more than a deep commitment to consilience: ensuring that the theories put forward in your research are as consistent as possible with the vast body of knowledge produced by all the sciences. Accordingly, the exact content of an evolutionary approach will continuously evolve as knowledge accumulates. Currently, evolutionary psychologists are mainly concerned with selection pressures operating within the small hunter-gatherer groups of our stone age ancestors because of the extremely limited pace of adaptation through natural selection. But if evolutionary biologists begin to discover examples of complex adaptations to modern environments, then this focus will shift too. The chief benefit of this 
commitment is that it serves as a straitjacket for the researcher's imagination. The need of such a straitjacket is clear from what is known as the replication crisis - the fact that the many published findings in the most prestigious psychology journals are most likely false or, at least, cannot be replicated by independent teams (Nosek et al., 2012). A central example of such non-replicable findings is the notion of subtle priming effects such that reminders of old age will induce you to walk slower (Doyen et al., 2012).

A consilient approach works against non-replicability by increasing the a priori robustness of a prediction by making it constrained by observations from biology, primatology, anthropology, history, and so forth. By narrowing the space for possible predictions, consilient approaches can speed up the scientific process. The old Popperian notion that science proceeds one falsification at a time leads to incredibly slow scientific progress, if all products of human imagination need to be tested and refuted. In contrast, consilience implies that we zoom in on those with greatest support from higher-order disciplines.

\section{Why Adaptations for Politics? The Politics of Ancestral Life}

Evolution is a slow process and takes generation after generation of stable selection pressures for complex adaptations to emerge. Evolutionary biologists have identified a number of recent adaptations relating to, for example, lactose tolerance and immunity against malaria (Cochran \& Harpending, 2009). The commonalities of these adaptations are, first, that the adaptive problems they

respectively solve are substantial and, second, that they only involve small genetic mutation. For complex psychological adaptations with more distal effects on reproduction, such as those involved in political judgment, it is the deep past that explains the present (Tooby \& Cosmides, 1990).

This implies that for adaptations for political judgment and behavior to exist the human past has had to be a political one. And there is indeed evidence for this. This claim may seem 
surprising if we think about politics in the sense of presidential elections, national media coverage, complex negotiations of bills, and so forth. It is less surprising if we zoom in on the essentials of politics. According to a classical definition, politics is about "who gets what" (Lasswell, 2018). In this perspective, politics is the process of negotiating access to resources. This requires, among other things, judgments about who is in the ingroup, how to divide resources within the group, and how to sanction those who take more than their share. If we strip away many of the legal and technical complexities of modern, national politics, these questions are at the core of most political debates about, for example, immigration, redistribution, and criminal justice. And such questions confronted our ancestors each day of their existence.

The human species has spent a predominant period of its existence as hunters and gatherers on the East African savannah, living in small groups of between 25 to 150 individuals and using stone age technology (Boyd \& Silk, 2014; Kelly, 2013). The core parts of human psychology (including human political psychology) are accordingly expected to have been adapted to this life.

Part of this life was oriented towards cooperation. The archaeological record shows a clear, early, and important role of food-sharing and collective hunting in human evolutionary history, and these aspects are also present in closely related species, including chimpanzees (Kaplan et al., 2000). The archaeological record also shows that there is substantial fossil evidence for traces of what in present terms would appear as empathy. Thus, archaeological investigations provide clear demonstrations of health care for immobile or severely handicapped group members, which kept them alive over several years (Hublin, 2009).

While this may be reminiscent of Rousseau's notion of ancestral humans as "noble savages," it is important to note that from an evolutionary perspective cooperation is always a wary enterprise. As will be discussed in more detail, there are always selective advantages to free-ride, in particular, if the free-rider can keep the cooperation going but subtlety extract more from the 
cooperative enterprise than is being invested. There is clear evidence of such complex cooperative dynamics within non-human primates (De Waal, 1996) and, of course, the importance of free-riding in humans is extremely well-documented (Albanese \& Van Fleet, 1985).

But the complexities of ancestral human social life go further. Thus, there is also significant evidence for the alternative notion to Rousseau's: the Hobbesian notion that the ancestral life could be "nasty, brutish, and short." There is clear fossil evidence of weapon-inflicted injury and death (Churchill et al., 2009). While prehistoric evidence in favor of more widespread conflict such as direct war is disputed (Gat, 2008), there is clear evidence of mass killing from about 10,000 years ago (Bowles, 2009), leading researchers to argue that warfare has constituted a heavy selection pressure on our species. Furthermore, while warfare - in the sense of group behavior with the purpose of killing members of other groups - is zoologically rare, it is relevant to note that two of the few species that engage in warfare are humans and chimpanzees. This provides some suggestive evidence that the last common ancestor may have engaged in such behavior too, implying that warfare may date back as early as 1.7 million years ago (Wrangham \& Glowacki, 2012). 
Table 1. Overview of Families of Adaptive Problems and their Involved Threats, Benefits, and Cues

\begin{tabular}{|c|c|c|c|c|}
\hline $\begin{array}{l}\text { Family of Adaptive } \\
\text { Problems }\end{array}$ & $\begin{array}{c}\text { Threats } \\
\text { to Fitness } \\
\end{array}$ & $\begin{array}{c}\text { Benefits } \\
\text { to Fitness }\end{array}$ & $\begin{array}{c}\text { Example Cues } \\
\text { to Threats }\end{array}$ & $\begin{array}{c}\text { Example Cues } \\
\text { to Benefits }\end{array}$ \\
\hline Physiological needs & $\begin{array}{l}\text { Starvation, dehydration, } \\
\text { overheating, etc. }\end{array}$ & Nutrients, liquids, etc. & $\begin{array}{l}\text { Internal physiological } \\
\text { imbalances }\end{array}$ & $\begin{array}{c}\text { External incentives associated with } \\
\text { past reductions of physical needs (e.g., } \\
\text { smell of food cooking) }\end{array}$ \\
\hline Self-protection & $\begin{array}{l}\text { Violence from other people; } \\
\text { contagious diseases }\end{array}$ & $\begin{array}{l}\text { Safety provided by } \\
\text { others }\end{array}$ & $\begin{array}{c}\text { Presence of unfamiliar, } \\
\text { dissimilar, angry males; being in } \\
\text { unfamiliar surroundings; } \\
\text { darkness; unfamiliar smells }\end{array}$ & $\begin{array}{l}\text { Presence of familiar, similar others; } \\
\text { being in familiar surroundings }\end{array}$ \\
\hline Affiliation & $\begin{array}{c}\text { Exposure to disease, } \\
\text { cheating/free-riding, } \\
\text { incompetence, excessive } \\
\text { demands }\end{array}$ & $\begin{array}{l}\text { Share resources, receive } \\
\text { material support, } \\
\text { enhanced self-protection, } \\
\text { access to mates } \\
\end{array}$ & $\begin{array}{l}\text { Subject "foreignness" of others; } \\
\text { unfamiliarity of other; other's } \\
\text { acts of cheating or norm } \\
\text { violation }\end{array}$ & $\begin{array}{l}\text { Familiarity; past acts of reciprocity, } \\
\text { trustworthiness; others' adherence to } \\
\text { group norms; facial characteristics } \\
\text { signaling trustworthiness }\end{array}$ \\
\hline Esteem/status & $\begin{array}{c}\text { Loss of status, social regard, } \\
\text { status-linked resources, and } \\
\text { mates }\end{array}$ & $\begin{array}{c}\text { Status-enhancing } \\
\text { alliances, access to } \\
\text { resources and (for males) } \\
\text { status opportunities }\end{array}$ & $\begin{array}{l}\text { Nonverbal dominance displays } \\
\text { by others; shifts in exchange } \\
\text { rules; lack of apparent respect } \\
\text { from others }\end{array}$ & $\begin{array}{l}\text { Nonverbal status-conferring displays } \\
\text { (e.g., eye contact, bodily orientation, } \\
\text { etc.) by others; shifts in exchange rules; } \\
\text { others' willingness to invest in oneself }\end{array}$ \\
\hline Mate acquisition & $\begin{array}{c}\text { Presence of desirable, same-sex } \\
\text { others }\end{array}$ & $\begin{array}{l}\text { Availability of desirable, } \\
\text { opposite-sex others }\end{array}$ & $\begin{array}{c}\text { Same-sex others' age, status, } \\
\text { symmetry, } \\
\text { masculinity/femininity, flirting } \\
\text { behaviors }\end{array}$ & $\begin{array}{l}\text { Opposite-sex others' age, } \\
\text { attractiveness, status, bodily symmetry, } \\
\text { morphological abnormalities, scent, } \\
\text { nonverbal flirting behaviors }\end{array}$ \\
\hline Mate retention & Sexual infidelity, mate poaching & $\begin{array}{l}\text { Long-term parental } \\
\text { alliances }\end{array}$ & $\begin{array}{l}\text { Partner flirtation behaviors; } \\
\text { presence of nearby, high mate- } \\
\text { value, opposite-sex individuals }\end{array}$ & $\begin{array}{l}\text { Others' expressions of love, intimacy, } \\
\text { commitment; others' and own age (i.e., } \\
\text { postmenopausal females) }\end{array}$ \\
\hline Parenting & $\begin{array}{c}\text { Especially high costs imposed } \\
\text { by children, cuckoldry (for } \\
\text { males) }\end{array}$ & $\begin{array}{l}\text { Enhanced reproductive } \\
\text { fitness }\end{array}$ & $\begin{array}{l}\text { Signs of distress in own } \\
\text { children; apparent physical } \\
\text { (dis)similarity of child }\end{array}$ & $\begin{array}{l}\text { Proximity of own children; nonverbal } \\
\text { cues eliciting care (e.g., smiles) }\end{array}$ \\
\hline
\end{tabular}

Notes. Table adapted from Kenrick et al. (2010). 
This was the likely life of our ancestors, a life-long camping trip without supermarkets, hospitals, and professional law enforcement. Our ancestors were constantly dependent other individual's willingness to channel resources towards them in the form of food, social support, and health care; constantly needing to monitor whether others were exploitive; and constantly in danger from not just predators (from big cats to cave bears) but also from other groups who were seeking to gain violent access to food-related resources and mates. Kenrick et al. (2010) has provided an overview of some of the most central adaptive problems in this environment, reproduced here as Table 1.

Table 1 is organized around seven sets of adaptive problems that have influenced our ancestors' survival and reproduction substantially. The columns lists the adaptive costs ("Threats to fitness") and the adaptive benefits ("Benefits to fitness") associated with the problems and their solutions, respectively. Furthermore, the columns list some key cues that the evolved mind is expected to use in order to identify situations that may entail either costs ("Example cues to threats") or benefits ("Example cues to benefits"). For example, problems associated with self-protection entails numerous threats including the threat of physical violence and the threat of infection. Importantly, however, self-protection can also be increased by relying on other individuals who can either provide support against attackers or provide health care when sick. Threats to self-protection are identified using a number of cues including the presence of angry males in unfamiliar surroundings. The presence of familiar others, in contrast, serve as a cue of safety.

For the present purpose, the key point is that navigating the compound of adaptive problems laid out in Table 1 - especially, self-protection, affiliation, and status-related problems required a sense of politics: an understanding of "who gets what, when, and how" (Lasswell, 2018). And the fact that you, the reader, is able to read this book - even the mere fact that you exist - is a testament to just how well-developed and effective this sense was and is. The human group that gave rise to the rest of the world's population ventured out of East Africa around 60,000 years ago (Boyd 
\& Silk, 2014). It took their descendants perhaps 20,000 years to reach Europe, a little more to reach Asia and Australia, and 20,000 years more to reach the Americas. Throughout this conquest of Earth, they lived in small groups of hunters and gatherers with stone age technology, aided chiefly by an incredible social and political mind. Ten thousand years ago, agriculture emerged, sustaining larger sedentary groups and, as result, cultural evolution accelerated with incredible speed. Within what is the evolutionary equivalent to the blink of an eye, the human political mind exploited this new dynamic to concentrate power within increasingly powerful and technologically advanced states, a process that has continued until the present.

\section{How Evolution Builds Adaptive Minds}

We just discussed how adaptive problems drive forward the process of natural selection to create adaptations with tailored designs to solve particular reproductive challenges. As noted, many such adaptations will be psychological adaptations and many of those will have evolved to deal with issues of political judgment and behavior. We will now dissect what this actually means.

Imagine that you were playing a computer game, and in the game your job was to program an avatar. The avatar was placed in an environment equivalent to ancestral human environments and the avatar had physiological needs equivalent to a human in terms of energy, oxygen, and so forth. Also, the avatar could - with the help of another avatar - replicate itself. The goal of the game was to get the avatar to reproduce as much as possible.

If you think of this challenge, you will quickly realize two things. First, you will realize that you cannot simply tell the avatar to "go reproduce" (sometimes referred to as a preference for fitness maximization; Tooby \& Cosmides, 1992) because reproduction requires the solution of an extraordinary amount of other, more specific problems: avoiding being eaten by predators, finding food, finding a mate, nurturing the offspring, and so forth. 
Second, you will realize that the challenge is that a computer avatar is exactly that: an unthinking computer product without everyday notions of consciousness, free will, or rationality. Accordingly, you need to program the avatar through conditional rules: if $x$ then $y$. For each problem, the decision rule needs to solve two subproblems: cognitive identification and behavioral solution (Tooby et al., 2005). To solve the problem of cognitive identification, a decision rule needs to contain lists of cues (and sub-algorithms for adding cues to that list) that discloses an adaptive problem (e.g., identifying an approaching enemy, identifying a valuable cooperation partner, or identifying an act of exploitation in a social relationship). To solve the problem of a behavioral solution, the decision rule - upon identification of a problem - needs to activate the mental and behavioral set of responses that solves the problem (e.g., running away when a predator is detected at a distance, preparing to fight when an enemy approaches, or putting on the charm when an attractive potential mate expresses interest in you). In this regard, there is nothing to hinder you from programming the avatar with learning processes in the form of feedback systems that learn from trial and error or imitation that allow it to emulate successful other avatars. But the key point is that the systems required for learning are themselves highly structured if- $x$-then- $y$ rules. The flexibility of your avatar that is necessary for success in the game hinges on the existence of having scores of decision rules rather than having a few (Tooby \& Cosmides, 1992).

In many ways, the functional target of natural selection and the mechanics of this game are not radically different and, accordingly, building hypotheses about how evolution has structured the human mind is very much similar to engaging in this thought experiment.

The functional perspective on the human mind entails that content-rich decision-making mechanisms exist and emerge as a reliable part of normal developmental processes. The notion that these mechanisms are content-rich implies that they contain, first, cognitive categories--sometimes referred to as types, templates or schemata--such as "parent," "sibling," "offspring," "friend," 
"enemy," "cheater," "ally," "follower," and "leader"; second, that they contain algorithms for the identification of each of these categories; and, third, that they contain algorithms for activating adaptive behavior towards each of these categories (Boyer, 2008).

As an illustration, take the concept of "sibling." It is key to reliably track who you are closely genetically related to. To increase so-called inclusive fitness (i.e., the total fitness of yourself, your offspring, your offspring's offspring, etc.), you need to direct resources towards them. To ensure genetic recombination, however, a specific type of positive emotion (romantic feelings) should be directed away from them. The issue is that our ancestors had no access to the underlying feature of hard reality - the degree of overlapping genes - that really determined whether this emotional and behavioral package of "brotherly love" was adaptive. Nonetheless, natural selection could act on the statistical regularities of ancestral environments to select for information-processing mechanisms that were able to identify siblings through cues that predicted relatedness under these circumstances. In particular, research shows that humans identify older siblings through the number of years of coresidence, while young siblings are identified by observations of perinatal nurture from one's mother (Lieberman et al., 2007; Tanskanen et al., 2021). These cues activate the narrow set of motivations that are adaptive towards siblings: increased feelings of altruism as well as increased disgust reactions towards the idea of engaging in sexual activity. In modern societies cues such as co-residence may not be a good actual predictor of relatedness. Modern family patterns imply that we may grow up with someone who we are not related to and may not grow up together with those we are related to. For modern individuals, there may thus be a disconnect between who they know are their siblings and which individuals fulfil the input conditions of the mechanisms designed by evolution to detect siblings. Research shows that in those circumstances the cues rather than explicit knowledge dominate our emotional responses towards others (Lieberman et al., 2007). 
This example contains a key point: Evolved psychological mechanisms process cues. If a cue fits the input conditions of a specific psychological mechanism, this mechanism will be activated, even if it leads to outcomes that are not necessarily adaptive today. In this way, modern citizens use their evolved psychology from small-scale ancestral groups to solve problems inherent to large-scale modern groups such as redistribution, crime and punishment, and immigration. It also implies that the factors and solutions that this evolved psychology pushes our attention towards are primarily the factors and solutions that were relevant in small-scale societies and which may or may not be helpful in the context of today.

\section{A non-intuitive perspective on decision-making}

As a reader, you might have a knee-jerk reaction against this comparison between your own psychology and a computer program. Yet, the key insight from cognitive science is that both the computer and the mind do the exact same thing: computations (Pinker, 2003). So, at least, some parts of your psychology will work in a way similar to a computer. The discussion within cognitive science is mostly how much. In this discussion, the position among (most) evolutionary psychologists is both simple and extreme as the computer-metaphor is seen as applicable to all parts of the human mind.

To understand this position, it may be relevant to compare it to the positions of other approaches to the mind. Many political scientists will be familiar with if- $x$-then- $y$ decision rules from the early work in political science and political psychology on heuristics, that is, easy-to-use rules of thumb (Sniderman et al., 1993). One well-studied heuristic in political reasoning is the heuristic to use information about the proposer of a political proposal to predict the content of the proposal (Kam, 2005). The information-processing mechanisms studied by evolutionary psychologists are in logic similar to such heuristics in that they are facultative rules for decision-making. At the same time, the details of these accounts differ dramatically. 
The classical claim within the political science research on heuristics has been that such decision-rules are (a) few in number; (b) learned from exposure to political debate; and (c) provide a shortcut to reach conclusions that could also be reached through effortful political reasoning (Sniderman et al., 1993). In contrast, an adaptationist perspective entails that such decision-rules are (a) incredibly plentiful, corresponding to the incredible number of adaptive problems our ancestors would need to solve to survive and reproduce; (b) emerge reliably as part of the normal developmental process of our species; and (c) are designed to propel behavior, contingent on the specific parameters of the situation, that would have been fitness-enhancing under ancestral circumstances (Petersen, 2015).

This contrast between the traditional perspective on decision-making mechanisms within political science and an adaptationist perspective is essentially about contrasting views about the psychological reality of the sense of self. The traditional view takes the phenomenological experience of making a decision at face value: In this view, there is indeed a central controller - you - who is able to figure out "smart moves" for making decisions (Sniderman \& Bullock, 2018). In the cognitive psychological perspective underlying evolutionary approaches, there is no such central controller. Just as the feeling of the solidity of a table is a misleading representation, created by our minds, of the actual quantum physics of the table, so too is the feeling of the existence of a central decision-maker (Barrett \& Kurzban, 2006; Kurzban \& Aktipis, 2007). Rather, your mind - including your sense of control - emerges from a massive collection of information-processing mechanisms (referred to as the principle of massive modularity), each designed to carry out a specific function (referred to as the principle of domain-specificity). Think of the way you catch a ball. Underneath that feeling of "this is when and where I need to put out my hand to catch the ball" there is a multitude of extremely well-designed mechanisms operating, continuously solving differential equations to 
predict the trajectory of the ball. The position of many evolutionary psychologists is that this is the rule rather than the exception for how decision-making works.

In recent decades, a popular midway position has been formulated by behavioral economics and social psychology in the form of dual-process theories. This midway position suggests that parts of our mind are a collection of parallel and unconsciously operating mechanisms as captured by the adaptationist notion of evolved domain-specific mechanisms (often referred to as "system 1" processes), and parts of our mind conform to the felt sense of central control, whereby conclusions are derived through effortful reasoning (often referred to as “system 2" processes) (Kahneman, 2011). Within dual-process theory, these two systems are often seen as alternatives such that you can reach a given decision either through one type of process or through the other (by either thinking fast or thinking slow). This midway position conforms strongly to the phenomenology of being human, with centrally set goals that are constantly disturbed by impulses and urges, which is also reflected in the age-old distinction between affect and reason.

While dual-process theories openly acknowledge the influence of evolved decisionmaking mechanisms, many evolutionary psychologists are still critical of such theories (Barrett, 2014; Kurzban, 2011). Evolutionary psychologists would agree that decision-making can indeed be either slow or fast. But the time and effort spent does not reflect the use of qualitatively different processes placed along a bipolar continuum from slow to fast. Instead, decision-making time and effort reflects the quantity of domain-specific processes being activated to solve a specific decision-making problem. Slow decision-making reflects the application of more functional mechanisms rather than fewer. Indeed, some of these domain-specific mechanisms may have evolved for tasks of slow reasoning such as causal reasoning (Quillien \& German, 2021) or mental time travel (Boyer, 2008). At a more philosophical level, many evolutionary psychologists would also argue that dual-process theories face significant problems as such theories do not solve the deep theoretical problems related 
to the presumed existence of a centrally controlled "self", even if this "self" retreats to occupy just some parts of the human mind (Barrett, 2014).

In the view of evolutionary psychologists, your sense of self emerges from myriads of more or less independently operating mechanisms (Kurzban, 2011). This may seem unbelievable. But, if you think about, it is not more unbelievable than something that we know is a fact: This sense of self, in the end, is nothing more than electric signals moving along the appendages of cells as little as a few micrometers in diameter. In this sense, a core requirement of an adaptationist approach is to put aside your folk (i.e., everyday) intuitions about how you and your fellow con-specifics reason and follow the logic of adaptationism wherever it brings you. In this sense, an adaptationist stance is remarkably similar in spirit to quantum physics with its dictum of "shut up and calculate" (Mermin, 2004).

\section{Illustrations of Evolutionary Political Psychology}

In their understanding of politics, most political psychologists focus on the mass level, that is, at the level of states and nations. From an evolutionary perspective, however, politics is a process that is being played out at many other levels. Politics is about resource allocation and, hence, is also something that occurs, for example, within families and in the local community. In fact, the problems of resource distribution and allocation within these smaller-scale social domains will better reflect the kinds of problems we evolved to deal with. Furthermore, because politics is fundamentally about resource allocation, politics is shaped by each and every problem that humans face, today and ancestrally. All of the problems listed in Table $1-$ and the psychological mechanisms selected to efficiently solve these problems - will accordingly shape the political attitudes and behaviors of modern citizens. 
For example, there is already evidence that problems related to immediate physiological needs shape modern political cognition. Sleep patterns, for example, are associated with political ideology, such that conservatives are more likely to be morning people (Ksiazkiewicz, 2020). Also, experiences of hunger and lack of access to calories have been found to increase support for helping the poor, potentially reflecting that sharing was a key strategy for buffering hunger ancestrally (Aarøe \& Petersen, 2013).

The problems of mate acquisition and retention have also been found to shape political choices. For example, individuals who seek more sexual partners have consistently been found to reject the influence of authorities on life choices, making them more left-wing on a number of cultural issues. In contrast, individuals who are seeking to retain their partners are more likely to endorse strong regulation of life choices (Petersen, 2018). Furthermore, research shows that people who are trying to attract new partners are more likely to hide their partisan allegiances (Klofstad et al., 2012), potentially because such allegiances are intuitively viewed as group attachments that hinder the possibility of cross-group bonding.

Problems of parenting also shape political choices. Both parenthood and the subjective motivation to become a parent have been found to increase risk aversion and make people more conservative (Kerry \& Murray, 2018). This effect presumably reflects that conservative social policies are often protection-oriented and, hence, cater to the increased sensitivity to risks.

Problems of physiological needs, mating, and parenting may seem distal to politics but nonetheless they shape political choices. In the following, we will take a more detailed look at the remaining problems from Table 1 - problems of self-protection, affiliation, and status - and discuss research that illustrates how these problems have selected for powerful political-psychological mechanisms that shape modern political attitudes and behavior. As these problems relate to problems of social relationships between non-kin, they are particularly relevant for the study of politics in 
modern mass society. At the same time, it is important to stress that these three adaptive problems are not uniquely relevant to politics.

\section{Self-protection: The politics of disease avoidance}

Pathogens are one of humanity's oldest enemies - in fact, one of the oldest enemies of all living creatures. Most people are acutely aware of how pandemics have killed millions throughout modern history and the biological immune system is a standard part of school curricula. Yet, still most people may not appreciate just how fundamentally the human species has been shaped by the fight against pathogens. For example, a central hypothesis in evolutionary biology is that sexual reproduction that is, that it takes two sexes to reproduce - evolved as a protective feature against pathogens as continuous genetic recombination limits their possibilities of adaptation (Tooby, 1982). Similarly, there is emerging evidence that humans developed several and distinct dynamic protective systems against exposure to pathogens. The immune system protects the body once pathogens get inside. In addition, psychological science shows the existence of mechanisms for avoiding exposure to pathogens in the first place.

This behavioral immune system evolved to detect cues that ancestrally disclosed the presence of a potential pathogen threat and, upon detection, motivate avoidance of the source through the emotion of disgust (Schaller \& Park, 2011). This helps explain disgust reactions and avoidance behavior towards feces, blood, rotten food, and so forth. Furthermore, because the detection of invisible threats such as pathogens is difficult and because a failure to detect the threat is potentially fatal, the evidence suggests that the behavioral immune system operates in a hypervigilant manner ("better safe than sorry") and, accordingly, may trigger in circumstances that may not be objectively threatening. Studies show, for example, that people experience disgust reactions against harmless props that simply look like excrements or completely disinfected glasses that only touched disease 
vectors prior to disinfection (e.g., Rozin et al., 1986). Finally, the key disease vector over human evolutionary history was other humans and, hence, the behavioral immune system is also highly vigilant towards signs of human infection symptoms such as rashes. However, the hypervigilant operations of the system also imply that even non-infection-related deviations from the average phenotype can trigger the system such as birthmarks or obesity (Petersen, 2017; Ryan et al., 2012).

The behavioral immune system is intimately tied to social behavior. It is triggered by the presence of other people and it motivates avoidance of other people (Aarøe et al., 2016). Accordingly, it is also expected that the operations of the behavioral immune system influence political attitudes and behavior. Researchers have, in particular, studied this influence through the lenses of individual differences in the activity of the behavioral immune system. Some people largely due to genetic factors (Sherlock et al., 2016) - are more sensitive to the presence of pathogens and a range of studies have looked at how individual differences in this sensitivity predict political individual differences.

The general finding from these studies is that the behavioral immune system does indeed shape political attitudes and behaviors in multiple ways. In particular, it shapes the perceptions of other people in society. People who are more prone to experience disgust are more distrusting of strangers (Aarøe et al., 2016) and especially of groups that deviate from the mainstream such as immigrants, homosexuals, and the homeless (Aarøe et al., 2017; Clifford \& Piston, 2017; Terrizzi et al., 2010). This also directly influences political opinions such that people who are higher in behavioral immune sensitivity are more likely to, for example, oppose policies that allow for immigration and same-sex marriage.

The opinion effects of the behavioral immune system have broader downstream effects. Leeriness of outgroups is, for example, associated with right-wing positions on cultural and social issues. Consistent with this, research finds that behavioral immune sensitivity is associated with a 
more right-wing self-placement on the ideological spectrum and a greater tendency to vote for rightwing parties (Aarøe et al., 2020; Terrizzi et al., 2010). This association between culturally right-wing views and behavioral immune sensitivity expands beyond the anglophone world, which has been the location of the majority of studies. Specifically, Tybur and colleagues examined the relationship between behavioral immune sensitivity and right-wing authoritarianism in 30 countries from all parts of the world, finding a culturally robust positive association (Tybur et al., 2016).

The initial work on the political psychology of disease avoidance focused on attitudes towards foreigners (Faulkner et al., 2004; Navarrete \& Fessler, 2006) and, in general, this is the area where most work has been done to understand exactly why disease avoidance motivations fuel political attitudes and why it matters. As an illustration of how to unpack empirical evolutionarily grounded relationships, it is helpful to discuss this work in further detail.

Psychologically, it may seem surprising why heightened vigilance towards pathogens will lead to opposition to immigration and leeriness of foreigners. One possibility raised in early work was that the behavioral immune system was designed by evolution to specifically attach higher disease threat to people from outgroups because they could host pathogens that the ingroups physiological immune systems were not adapted to fight (e.g., Faulkner et al., 2004). In this perspective, the effect would reflect an adaptation. For a number of reasons, however, this argument is evolutionarily implausible (see Aarøe et al., 2016), in part because our ancestors were travelling on foot and would very seldomly get into contact with groups with completely different pathogen ecologies. Consistent with this, empirical research finds that foreigners with infection symptoms are not viewed as a greater disease threat than ingroup members with similar infection symptoms (van Leeuwen \& Petersen, 2018).

Another possibility is that the relationship between the behavioral immune system and opposition towards foreigners reflects the hypervigilance of the system. Put bluntly, a difference in 
skin color is wrongfully mentally tagged as a potential infection symptom in the same way that a birthmark is (Aarøe et al., 2017; Petersen, 2017). In this perspective, the effect of the behavioral immune system on xenophobia would not be an adaptation but a by-product. There is some evidence for this possibility. Thus, research using unobtrusive measures of mental categorization shows that people mentally tag healthy but racially different foreigners as similar to ingroup members with a physical infection symptom such as a rash (Petersen, 2017). Hence, skin color is treated as equivalent to an actual infection symptom. In this perspective, the relationship between disease-avoidance motivations and xenophobia reflects a maloperation of a hypervigilant psychological system that evolved within a monoracial ancestral environment.

It should be noted that these two explanations do not exhaust the universe of possibilities. Especially, there is also evidence to suggest a third possibility (Karinen et al., 2019). The premise for this third possibility is that a key bulwark against pathogens is and was cultural practices related to, for example, cleaning, hygiene, and food-preparation. In this perspective, the relationship between disease concerns and xenophobia does not reflect that foreigners as such are mentally tagged as pathogen hosts but that the presence of foreigners is tagged as a threat against cultural equilibria that partly serves a disease-protection function.

Independent of the exact psychological mechanism underlying the relationship between disease-avoidance motivations and avoidance of outgroups, this relationship is important in the sense that it changes the challenges associated with establishing cooperative between-group relationships. In the literature on tolerance, for example, it is sometimes argued that people will be more tolerant towards members of other groups if these are presented as hard-working and willing to contribute to society. Yet, some evidence suggests that if intolerance is grounded in disease concerns, then information about the cooperativeness of foreign groups does not increase tolerance (Aarøe et al., 2017; but see Karinen et al., 2019). After all, the perception of threat is not grounded in the intentions 
of the individual but in the autonomous pathogens that the individual is misperceived to host. Furthermore, the literature on tolerance consistently promotes the argument that social contact is key for the promotion of tolerance (e.g., Crisp \& Turner, 2009). Yet, if intolerance is grounded in disease concerns, then the avoidance of social contact is deliberatively sought. In fact, there is some evidence to suggest that individuals high in behavioral immune sensitivity have a preference for racial segregation policies exactly because these entail social avoidance (Aarøe et al., 2017). In other words, knowing and understanding the way the evolved behavioral immune system shapes modern politics is key for understanding the challenges of achieving peaceful multiethnic societies.

\section{Affiliation: The politics of cheater detection}

The adaptive problem captured by Kenrick et al.'s (2010) term “affiliation" has been intensely studied within evolutionary biology under the heading "cooperation". In fact, the evolution of cooperation is probably one of the most studied questions within the broader evolutionary sciences as applied to humans. The extent of human cooperation is so zoologically distinctive that it is sometimes referred to as a key defining characteristic of our species (Bowles \& Gintis, 2011). Humans are, in the words of Tomasello (2014), ultra-social.

Cooperation has not only attracted significant attention because of its role in human life but also because it was - even for Darwin - an evolutionary puzzle. Cooperation entails sacrificing resources for another organism, which seems to clash with the notion of evolution as "survival of the fittest."

The puzzle was solved in two steps. The first step was taken by William Hamilton (1964) in his research on kin altruism. To the extent two organisms share genes, helping behavior of one organism towards the other could have evolved as the first organism essentially promoting its own genes through the behavior. This principle - and the underlying formalizations - readily 
explained cooperation between human kin and how this systematically varies according to genetic relatedness and also explains the behavior of other ultra-social species such as ants, because ants within any single colony are highly related.

The second step was taken by Robert Trivers (1971) in his work on reciprocity. Trivers turned towards the problem left unsolved by Hamilton: cooperation between non-related organisms. Trivers argued that such cooperation could have evolved if it was reciprocal, that is, if a helping act from organism A to organism B is returned and that for each act the benefit to the receiver is larger than the cost to the giver. The latter condition is fulfilled in many cases in which a need is present. The expected benefit to the receiver is often higher than the expected cost to the actor when saving one from drowning, when sharing food with one who is hungry, when supporting a friend against an aggressor, when showing how to build a tool, and so forth.

The more challenging condition is the former: ensuring that help is directed towards those who are disposed to return help. The formidability of this challenge reflects that there are strong selection pressures for free-riding or cheating, as Trivers termed the behavior. Cooperation is a collective action problem and is well-known among most students of politics - in part, because of how Trivers' work shaped the work of political scientists such as Robert Axelrod and Elinor Ostrom - because such problems involve the opportunity to harvest the benefits without paying the costs. There are incredible evolutionarily returns to cooperation but the problem of cheating implies that it has only evolved in non-kin forms within a select number of species. Furthermore, even for cooperative organisms such as humans, there is a constant selection advantage in so-called subtle cheating: cheating that is not so blatant that it curtails cooperation altogether but which nonetheless implies that someone reaps more than invested in the cooperative relationship. Consistent with this, evolutionary psychologists have produced a consistent line of evidence that humans have extraordinary capacities to detect violations of social expectations in exchange relationships 
(Cosmides \& Tooby, 2015), that these exist cross-culturally, operate independently of formal education (Sugiyama et al., 2002), and rely on functionally dedicated brain regions (Stone et al., 2002). Being a hyper-cooperative species comes with balancing hyper-vigilance towards potential situations of cooperation with hyper-vigilance towards potential acts of cheating. As demonstrated by decades of research in behavioral economics, the detection of such cheating leads to a quick withdrawal of cooperation, the elicitation of punitive sentiments, and a search for signs of remorse, if cooperation is to be reestablished (Ostrom \& Walker, 2003).

Beyond solving the problem of non-kin cooperation, Trivers' major achievement was an initial analysis of how the selection pressures related to reciprocity has profoundly shaped almost all aspects of human social cognition as also suggested in the preceding paragraph. From this analysis, researchers were provided with the building blocks for understanding key political phenomenon such as group formation (Tooby et al., 2006), leader choice (Price \& Van Vugt, 2014), punishment, and reconciliation (Petersen et al., 2012). In short, there is probably not a set of adaptive problems more important than reciprocity for understanding political behavior (see also Alford \& Hibbing, 2004).

An illustration is provided by research on the relevance of cheater detection for social welfare attitudes. Modern welfare states are probably the most complex system of exchange to have existed. Resources are exchanged between future, current, and past selves, between the fortunate and the unfortunate, and between generations. At the same time, the welfare state is an object of political disagreement. Some people in established democracies support having a large welfare state, others are more opposed.

A finding in early work on variation in welfare state attitudes was that this variation did not simply track self-interest but was strongly related to perceptions of welfare recipients and their so-called deservingness, that is, the degree to which these recipients were morally praiseworthy (see Oorschot, 2000). Furthermore, early work suggested that this moral judgment in particular tracked 
people's perceptions of whether the recipients were in control over their plight. For example, if recipients could work but chose not to, they were seen as significantly less deserving. Welfare is supported for recipients who are deemed to be unlucky but opposed for recipients deemed to be "lazy."

A number of different theories have been used to explain this variation. Some of argued that the use of deservingness judgments as a decision-making heuristic - with their focus on individual responsibility - is part of a right-wing ideology (Skitka \& Tetlock, 1993). Others have argued that deservingness judgments as heuristics are acquired from individualistic cultures such as the American (Gilens, 1999). Early explanations, in other words, pointed to a high degree to culturally particularistic explanations.

In an evolutionary perspective, in contrast, the focus on the luck and effort in helpgiving situations follows directly from the logic of cheater detection, even if those decisions are related to a complex modern institution such as the modern welfare state (Petersen, 2012; Petersen et al., 2012). The basis for variation between people in welfare attitudes is not whether people base their help-giving decisions on notions of desert but rather the content of the perceptions of their recipients, formed in part by the cues available about the specific recipient and in part on the basis of general impressions of the entire relevant social group (i.e., stereotypes built on personal experiences, cultural tropes, etc.).

Evolutionary work on cheater-detection had already established how people in both Western societies and small-scale horticultural societies rely on cues about luck and effort in their help-giving decisions (Cosmides \& Tooby, 1992). Establishing that these mechanisms also underlie deservingness judgments in modern politics, however, is not straightforward. It essentially entails what is sometimes called abduction, i.e., inference to the best explanation. As discussed earlier in this chapter, providing direct evidence for ultimate explanations is difficult. Instead, an ultimate 
explanation is often seen as supported within evolutionary psychology, if it constitutes the simplest inference on the basis of the available observations. Consistent with this, the argument that the evolved logic of cheater detection underlies modern welfare attitudes reflects numerous different lines of evidence that together make a strong case.

One critical experiment used a so-called memory confusion paradigm to demonstrate that the psychological mechanisms that we use to guide everyday decisions about help giving are the exact same psychological mechanisms that we use to guide political decisions about social welfare (Petersen, 2012). The crux of the paradigm is that situations processed by the same mechanisms are confused when recalled. In the specific study, participants were presented with a series of people receiving help in an everyday situation (e.g., getting help move to a new apartment) and a series of people receiving social welfare. In some of the situations, the recipient was clearly a reciprocator and in other situations the recipient was clearly a cheater. Upon recall, people confused cheaters with cheaters and reciprocators with reciprocators, independently of whether these had received everyday help or social welfare.

Another set of studies demonstrated a logical implication: deservingness judgments in welfare opinions should rely on automatic psychological mechanisms and be charged with emotions (Petersen et al., 2011; Petersen et al., 2012). For example, these studies showed that decisions were made more quickly when clear deservingness cues were available and relied on emotions such as anger (towards recipients low in effort) and compassion (towards unlucky recipients).

A third series of studies showed that deservingness judgments were not limited to particular cultural contexts. Thus, both people in individualistic countries, such as the United States, and people in more collectivistic countries, such as Denmark and Japan, rely on deservingness cues when forming welfare opinions (Petersen \& Arceneaux, 2020). One study examined the association 
between welfare opinions and deservingness judgments across 49 countries and found a significant association in all but one (Petersen et al., 2012).

Probably the best evidence against the argument that deservingness judgments are tied to particular cultures or ideologies comes from evolutionarily informed studies that focus on "crowding out" effects, that is, how the presence of one type of consideration can crowd out peoples' reliance on other types of considerations. These studies show that presence of just two sentences of deservingness cues essentially crowd out otherwise substantial cultural and ideological differences in welfare opinions. While Americans and Danes differ in their general support of their respective welfare states, these cultural differences disappear when judging specific welfare recipients described in ways that fit the evolved cheater-detection systems. Americans' and Danes' opposition towards granting welfare to a low effort recipient are statistically indistinguishable, as are their support for welfare for an unlucky recipient (Aarøe \& Petersen, 2014). Similarly, while people on the left-wing and right-wing differ in their general support for welfare benefits, these differences disappear in the face of cues that fit evolved cheater-detection mechanisms (Petersen et al., 2012). When Americans, Danes, people on the left-wing and people on the right-wing have different social welfare attitudes it is not because they are psychologically different in any fundamental way. It is because they have different understandings of whether the average welfare recipient is a free-rider or a reciprocator and those understandings trigger different evolved intuitions.

These findings imply that it is, at least, possible that social welfare opinions are heavily shaped by evolved mechanisms for cooperation. Prior to the application of an evolutionary perspective to welfare opinions, it was already known that welfare recipients' luck and effort played an important role in attitudes towards them. The evolutionary perspective contributes by providing an understanding of why this is the case. At the same time, this explanation also has important implications. One of them is that everyone should be swayed by political arguments that tap into 
evolved mechanisms related to cheater detection. Research has already provided some evidence for this, suggesting that framing individuals as cheaters is a universally strong strategy in political communication (Petersen \& Arceneaux, 2020).

\section{Status: The politics of status seeking}

The examples of how the psychologies of disgust sensitivity and cheater detection shape attitudes to immigration and welfare attitudes, respectively, illustrate two ways in which evolutionary psychology can inform political psychology. Disgust reactions is an example of a factor that researchers would probably not have thought of as socially and politically relevant without an evolutionary framework and shows how evolutionary psychology can point researchers in new directions. In contrast, political psychologists already knew that luck and effort played a major role in welfare attitudes prior to the application of evolutionary psychology. Here, the contribution of this application was instead to provide a deeper understanding - an ultimate explanation - of why these factors mattered.

In this section, we will examine a third and final illustration: status seeking as a way to explain hostile behaviors on social media. This illustration provides an example of yet another way in which the application of evolutionary theory can contribute to political psychology: challenging popular - and perhaps intuitive - explanations of phenomenon by considering a larger base of evidence.

Humans are group-living animals and, as noted earlier, harvest enormous cooperative surpluses from social life. Social life, however, is not just structured by horizontal relationships of cooperation but also by vertical relationships of hierarchy. The evidence from both human and nonhuman primates suggests that there are substantial selection benefits in terms of quantity and quality of offspring from having higher social status. As such there are substantial selection benefits from psychological mechanisms that facilitate the climbing the social hierarchy (Maner, 2017). 
Psychologically, social status is a shared expectation about a person's entitlement to resources. According to evolutionary models of hierarchy, this entitlement can be based on prestige (i.e., the delivery of services to voluntary followers) or on dominance (i.e., the extraction of resources from others through the induction of fear) (Maner, 2017). Evolutionary research suggests that individual differences that predict the success of each of these two strategies predicts their use. For example, individuals with greater physical strength - a major predictor of ancestral cost-imposition ability - are more likely to use aggression and dominance (Sell et al., 2009). This also applies to modern politics where physical strength predicts support for the use of military power and engagement in political violence (Bartusevičius, 2021; Sell et al., 2017). In fact, dominance motivations are some of the best predictors of actual participation in political violence across the world (Bartusevičius et al., 2020).

One particularly important feature of humans is that much conflict is group-based and, accordingly, that we also ascribe status to groups and compete over status. In essence, it is a collective good to be a member of a high-status group because of the special access to resources such membership entails (Tooby et al., 2006). A number of psychological mechanisms therefore also exist for advancing the status of one's group vis-à-vis other groups. Some of these mechanisms evolved to identify threats from other groups. Other mechanisms exist to mobilize your own group against other groups. One of the key tools for such mobilization is coordination of ingroup members' attention towards the threat by rapid information sharing (Petersen, 2020). Some of the best analyzed examples of such dynamics are from anthropological research on ethnic massacres. In his systematic review of what happens before, during, and after ethnic massacres, Donald Horowitz (2001) describes the role of rumor sharing in the following way:

"A rumor is a short-lived, unverified report, usually anonymous in its origin. No rumor that is disseminated widely enough to help precipitate collective violence can be understood as 
merely a chance falsehood or, as is commonly thought, a bit of misinformation that gains currency because official news channels have been remiss in putting out the truth. Concealed threats and outrages committed in secret figure prominently in pre-riot rumors. ... Rumors are structurally embedded in the riot situation, because they are satisfying and useful to rioters and their leaders, and so efforts to counter rumors may be misdirected. Rumor is likely to prevail over accurate information. ... Rumor prevails because it orders and organizes actionin-process.

In many domains it is key to have evolved machinery that provides the individual with accurate perceptions of the world. Our ancestors would, for example, need extremely accurate perceptions to be efficient hunters. But in social life accuracy is not always the key factor for selection (Kurzban, 2011). If improvements of personal or group status can be achieved by selectively dispensing with the truth it is likely that this will be favored by evolution. For a strategic social animal, information sharing is as much about influencing other people's behaviors in ways that are beneficial to the self as it is about broadcasting accurate portrayals of the world (Kurzban, 2011; Petersen, 2020). Essentially, that is Horowitz' point: Sharing misinformation is useful when mobilizing for conflict.

These theoretical notions stand in contrast to some of the ways in which a particular kind of rumor sharing has been explained: "fake news" sharing on social media. It may seem intuitive that people care about truth and when asked directly people also overwhelming emphasize the importance of only sharing true information (Pennycook et al., 2021). From this it follows that people who share misinformation mistakenly think the information is true or are distracted and do not attend to the information's truth value.

At the same time, misinformation in the form that has been the focus of the "fake news" debates in the United States shares multiple features with the kind of rumors that have been shown to be useful for mobilizing: They highlight that (1) there is an enemy group, which is (2) strong and (3) 
ready to aggress (Petersen et al., 2020). In the context of US party politics dominated by a two-party system, this enemy group is most often the other political party.

The empirical evidence suggests that ignorance certainly plays a role when it comes to beliefs in misinformation (Pennycook \& Rand, 2019). Yet, the theoretical point from an adaptationist perspective is that there may be a disconnect between beliefs and sharing. Sharing is a social act, aimed at accomplishing specific social goals such as mobilizing your ingroup and here accuracy might not always be that useful. Indeed, the evidence is also much weaker for the role of ignorance when it comes to sharing decisions. In fact, people who share false information online are more, not less, knowledgeable about politics than the average American (Osmundsen et al., 2021). Instead, what really drives fake news sharing is partisan animosity: hating members of the other political party (Osmundsen et al., 2021). Not only the content but also the psychological drives of the sharing of misinformation in contemporary democracies is horrifyingly similar to drives in ethnic riots.

Further evidence suggests that these sharing decisions are, at least in part, driven by attempts to acquire individual and group status through dominance. Psychological measures of dominance motivations are hugely predictive of the motivations to share false and hostile information online (Petersen et al., 2018). Research has also shown that the predictive power of dominance motivations extends to other problematic online phenomenon such as being hateful or engaging in so-called "moral grandstanding" in online debates (Bor \& Petersen, 2021; Grubbs et al., 2019; Petersen et al., 2021). In a nutshell, the same psychological factors that predict hostility in offline contexts also predict it in online contexts. Humans are human, whether they are online or offline. Indeed, there is evidence that dominance motivations (i.e., craving status among those who feel that prestige is outside their reach) are the common denominator of a very large range of the behavior that observers associate with the turmoil that many democratic societies face in current times, including online hate, the sharing of misinformation, violent protest, and support for dominant leaders that can 
further mobilize the masses against the perceived enemy (Laustsen \& Petersen, 2017; Petersen et al., 2021).

A deeper psychological - or, perhaps, even philosophical - point raised by these findings is about the relationship between beliefs and behavior. Do people who instrumentally share misinformation to gain the upper hand in status competitions with other groups believe in the misinformation or not? Few people would admit to circulating information they believed to be blatantly false and most would argue that they do believe the information they share. But that often begs the question: Do they really believe it? From an adaptationist perspective such a series of questions is misguided. What is consciously accessible to us - what we in some sense of the word "believe" - is what is useful to us, given the adaptive problem we are facing. Sometimes it is useful to hold beliefs that accurately represent reality. Sometimes it is not. Both are, from a phenomenological perspective, equally valid beliefs. Indeed, sometimes it is most useful for us to convince ourselves that what is useful is really accurate. The first step in persuading others is often to persuade yourself. Self-deceit (meaning that as there is no true "self," some parts of the mind are able to dominate conscious thinking at the expense of other parts of the mind) may be an adaptive strategy (Kurzban, 2011).

\section{When the Past Does Not Look Like the Present: The Role of Evolutionary Mismatches}

The earlier illustrations focus to a large extent on how adaptations for navigating ancestral politics allow people to navigate in modern politics with high degrees of efficiency. People intuitively react with avoidance towards those activating disease concerns; carefully tailoring support for help-giving based on cues of reciprocity; and strategically share those types of information that are most likely to mobilize others. 
This efficiency may seem to completely clash with the orthodoxies of political psychology: citizens do not really care about politics; they do not even know the most basic facts of politics; and they are not able to put together a coherent set of beliefs or even a stable political position (Achen \& Bartels, 2017). In a sense, for ostensible political animals, citizens are surprisingly politically unengaged (Petersen \& Aarøe, 2012).

In the earlier sections, we focused on how the similarities between adaptive problems and modern political issues trigger sophisticated decision-making machinery to guide political opinion formation and political behavior. The key triggers in this regard are the modern existence of information that resembles evolutionarily recurrent cues with adaptive significance. Yet, it is also clear that modern societies differ radically from ancestral societies in many respects. First, modern societies are technologically unrivalled, which creates a suit of political problems that there simply does not exist specific psychological adaptations to handle (such as nuclear power, genetically modified crops, and vaccine technology). Second, modern society involves interactions with millions of anonymous strangers, which implies that most political decisions are related to groups and people that individuals only have a faint, if any, acquittance with. As noted by Walter Lippmann (1929, p. 43), "our opinions cover a bigger space, a longer reach of time, a greater number of things, than we can directly observe." Both of these features of modern societies are examples of what evolutionary psychologists call "mismatches," that is, differences between the environment in which an adaptation evolved and the environment in which an adaptation is executed, which may cause adaptations to misfire or not fire at all.

The first mismatch - that is, the existence of novel problems in modern societies implies that if domain-specific psychological adaptations are activated, the intuitions they generate may not be helpful in actually solving the problem. Multiple examples come from the people's intuitions about macro-economic problems where intuitions tailored to small-scale social interaction 
miss key features of how the economy works (Boyer \& Petersen, 2018). Other examples come from the work on disgust sensitivity. For example, technological advances like genetically modified crops contain cues that activate disease-avoidance concerns (e.g., the tampering with something "natural"), which cause individual differences in disgust-sensitivity to predict opposition to such crops, although there is no actual link to contamination risk (Clifford \& Wendell, 2016).

The second mismatch - that is, the need to make political decisions about unseen others in mass societies - entails that the psychological mechanisms that rely on cues from face-to-face interaction in small-scale groups often cannot be executed. From an adaptationist perspective, this is the core reason why the political animal is so politically ignorant: This feature of mass societies obscures the linkages between many modern political problems and core adaptive problems of social interaction (Petersen \& Aarøe, 2012). Consistent with this, research has shown that a key difference between those who are and those who are not able to produce a strong opinion on a topic is the extent to which they are able to mentally simulate a clear representation of evolutionarily recurrent cues with relevance on the topic (Petersen \& Aarøe, 2013). Specifically, those who have a strong opinion on social welfare policies are those who clearly see social welfare recipients in general as either cheaters or reciprocators. Those holding ambiguous representations, or those lacking mental representations of this social group, cannot produce strong opinions, until provided with a clear specific description of a welfare recipient.

When making political decisions our minds were designed to scan for problems that recurrently occurred in small groups of hunters and gatherers and to implement solutions that recurrently solved problems in the same context. Accordingly, formulating hypotheses of whether our minds correctly identify problems and solutions in modern politics requires careful attention to similarities and differences between politics of now and then. This is consistent with whether the concept of ecological rationality, that is, that a psychological mechanism can only be said to be 
rational within the very narrow scope conditions that the mechanism evolved to deal with (Todd \& Gigerenzer, 2007). From this perspective, ignorance and irrationality do not reflect random reasoning mistakes but rather a systematic - and therefore predictable - response to mismatches between environments and mechanisms.

\section{What Evolutionary Psychology Is Not?}

In this chapter, I have tried to introduce a way of approaching political psychology that was considered unorthodox a few years ago and may still seem that way for some. As a consequence, more misunderstandings are likely to occur compared to an approach that is older and more wellacquainted. In this last section of the chapter, I will try to address some of the common misunderstandings by quickly describing what evolutionary approach to political psychology is not.

\section{An evolutionary approach is not behavior genetics}

Evolutionary psychology is not the only biological approach that has gained prominence within political psychology. The other approach is behavior genetics. Evolutionary psychology is oriented towards understanding the species-typical traits of humans, that is, what makes us similar. Behavior genetics is oriented towards understanding how genetic differences contribute to behavior differences, that is, what makes us different. Yet, sometimes even people well-versed in both approaches can conflate the two and make the leap that genetic effects on individual differences in a trait (a behavior genetics claim) imply that this trait evolved through natural selection (an evolutionary claim) (see, e.g., Smith et al., 2017, p. 432). But this is simply not the case.

It may sound strange but the fact of the matter is that many evolved traits will turn up as having zero genetic heritability when studied using behavior genetics methods such as twin studies. A somewhat extreme example can demonstrate this point. It should be clear to everyone that having 
two arms is a trait that evolved through natural selection and is genetically heritable. Yet, sometimes because of accidents, people will lose an arm or even both. In the classical twin design, this implies that the number of arms a person has will turn out to be driven by environmental and not genetic factors (e.g., one twin being the victim of a work-related accident lost their arm). From the perspective of behavior genetics, this is completely true because this approach is oriented towards individual differences and the causes of this difference are indeed environmental. But it should also be clearas behavior geneticists will recognize - that this has little implication for whether the species-typical trait (here, having two arms) is an evolved, genetically heritable trait.

All this does not imply that evolutionary political psychologists are not and should not be interested in the origins of individual differences. They are and should be. The approach of the evolutionary psychologist is here to focus on the structure of any information-processing machinery that determines the variation across individuals and on this basis build a hypothesis on the drivers of this variation. As discussed in detail by Buss (2009), these drivers can include genetic, developmental, and situational factors.

An evolutionary approach is not rational choice theory

Because of its focus on fitness costs and benefits, an evolutionary approach may appear as if it is simply a form of rational choice theory, where the cost-benefit calculations are in terms of reproduction rather than money. It is indeed true that there are similarities in the tools used by rational choice theorists and evolutionary biologists: evolutionary biologists also make repeated use of game theory. But the psychological theories of evolutionary psychology and rational choice are completely different.

Organisms are not fitness maximizers in the sense that they have a conscious goal of maximizing reproduction in the same way that rational choice theorists postulate a conscious goal of 
maximizing utility. Organisms are, instead, adaptation executioners, making decisions on the basis of psychological mechanisms that on average increased fitness in ancestral environments but may or may not do so in the specific application and in the current environment (Tooby \& Cosmides, 1992). For example, While the logic of reciprocity has shaped our help-giving psychology, it does not mean that we help one another with the conscious goal of being helped in return. We may simply help because we sympathize with the other or feel compassion. But these emotions, in turn, have been selected to be regulated, in part, by cues that under ancestral circumstances tracked the likelihood of reciprocation.

An evolutionary approach is not opposed to learning, socialization, and culture

Individuals vary and societies vary across time and space. Evolutionarily minded researchers are interested in understanding this variation. While many standard political psychology approaches would use terms such as learning, socialization, or culture to explain such variation, evolutionary psychologists would focus on (1) the structure of relevant universal psychological mechanisms and (2) variations in the local availability of information to activate those mechanisms. Thus, a constant can explain variation if this constant is a specification of an input-output relationship (like a mathematical function or a psychological mechanism).

It is relevant to think of the way this local variation in information ecologies is turned into local variation in behavior through highly structured information-processing mechanisms as instances of what we would call "learning," "socialization," and "culture." Essentially, evolutionary psychologists would argue that this more complex description is an attempt to open up the "black box" arguments that often underlie people's allusions to, for example, learning.

An evolutionary approach is not a normative theory 
We have noted how mismatches between ancestral and modern environments may create irrational responses. Yet, it is also relevant to highlight a different form of mismatch: human nature as it is empirically and what we as a community find normatively desirable. As is well-known from political philosophy, there is a gulf between is and ought, and natural selection has selected many traits that are deeply problematic from a normative perspective.

It is of key importance to stress that theories from evolutionary approaches are not normative theories in the sense that they do not entail anything about the desirability of the traits under investigation. Even within the environments in which our psychology evolved to operate, we cannot assume that evolved responses are necessarily good, just, or fair, as the earlier illustrations relating to prejudice, violence, and misinformation make clear.

At the same time, raising awareness of these problematic traits - and exploring their exact origin and structure - will most likely help researchers and policymakers achieve fairer and more just societies; for example, by enabling policymakers to create institutions that buffer against the obstacles that such traits create.

\section{Conclusion}

Any student of psychology will quickly observe that human psychology operates in mysterious ways. According to the observations in this chapter, however, human psychology is even more mysterious than one may realize from mere observation. An evolutionary framework implies that the human mind is comprised of endless numbers of task-specific mechanisms, optimized by natural selection to solve the myriads of problems that our ancestors faced, generation after generation, in their smallscale groups of hunters and gatherers. What seems like an "I" in charge of decision-making is nothing more than the format by which the negotiated output of these mechanisms reveals itself in conscious thought (Wright, 2017). 
Many of the problems facing our ancestors were strictly political in nature and related to the division of resources within and between groups. We are born with political minds, containing mechanisms that continuously scan our environments for political problems in need of solutions. In contrast to the standard view of citizens as politically ignorant, citizens are, by nature, politically sophisticated, with minds that evolved to, for example, invest resources in particular individuals, aggress against others, and if needed, mobilize their group to help carry out these tasks.

Yet, politics is no longer just a small-scale community phenomenon. For example, the alleviation of the plight of those in need is now carried out by welfare states of millions; punishments of norm violators are meted out by criminal justice systems, regulated by criminal codes; and the migration of individuals from one social group to another is regulated by international law. Still, our evolved minds continue to scan for the problems of small-scale social living and intuitively reach for the solutions that worked within such an environment.

While citizens are politically sophisticated, their attitudes and behavior in modern society will therefore often appear ignorant and irrational. Perhaps paradoxically, this ignorance and irrationality is the product rather than refutation of the sophistication of the mind's political machinery. It is exactly because the human mind was built to assume an ancestral environment, that it often fails in the modern one. By understanding the structure of ancestral social environments and the psychological imprints left by them, researchers can thereby encompass both the rational and irrational sides of modern politics within a single coherent framework and predict when one will dominate the other. This is the promise of an evolutionary approach to political psychology.

\section{References}

Aarøe, L., \& Petersen, M. B. (2013). Hunger games: Fluctuations in blood glucose levels influence support for social welfare, Psychological Science 24(12), 2550-2556. 
Aarøe, L., \& Petersen, M. B. (2014). Crowding out culture: Scandinavians and Americans agree on social welfare in the face of deservingness cues, The Journal of Politics 76(3), 684-697.

Aarøe, L., Osmundsen, M., \& Petersen, M. B. (2016). Distrust as a disease avoidance strategy: Individual differences in disgust sensitivity regulate generalized social trust, Frontiers in Psychology 7, 1038.

Aarøe, L., Petersen, M. B., \& Arceneaux, K. (2017). The behavioral immune system shapes political intuitions: Why and how individual differences in disgust sensitivity underlie opposition to immigration, American Political Science Review 111(2), 277-294.

Aarøe, L., Petersen, M. B., \& Arceneaux, K. (2020). The behavioral immune system shapes partisan preferences in modern democracies: Disgust sensitivity predicts voting for socially conservative parties, Political Psychology 41(6), 1073-1091.

Achen, C. H., \& Bartels, L. M. (2017). Democracy for Realists: Why Elections Do Not Produce Responsive Government. Princeton, NJ: Princeton University Press.

Albanese, R., \& Van Fleet, D. D. (1985). Rational behavior in groups: The free-riding tendency, Academy of Management Review 10(2), 244-255.

Alford, J. R., \& Hibbing, J. R. (2004). The origin of politics: An evolutionary theory of political behavior, Perspectives on Politics 2(4), 707-723.

Barrett, H. C. (2014). The shape of thought: How mental adaptations evolve. Oxford: Oxford University Press.

Barrett, H. C., \& Kurzban, R. (2006). Modularity in cognition: Framing the debate, Psychological Review 113(3), 628.

Bartusevičius, H. (2021). Physical strength predicts political violence, Evolution and Human Behavior 42(5), 423-430. 
Bartusevičius, H., van Leeuwen, F., \& Petersen, M. B. (2020). Dominance-driven autocratic political orientations predict political violence in Western, educated, industrialized, rich, and democratic (WEIRD) and non-WEIRD samples, Psychological Science 31(12), 1511-1530.

Ben-Nun Bloom, P. (2014). Disgust, harm, and morality in politics, Political Psychology 35(4), $495-513$.

Bor, A., \& Petersen, M. B. (2021). The psychology of online political hostility: A comprehensive, cross-national test of the mismatch hypothesis, American Political Science Review, 1-18. doi:10.1017/S0003055421000885

Bowles, S. (2009). Did warfare among ancestral hunter-gatherers affect the evolution of human social behaviors? Science 324(5932), 1293-1298.

Bowles, S., \& Gintis, H. (2011). A cooperative species. Princeton, NJ: Princeton University Press.

Boyd, R., \& Silk, J. B. (2014). How humans evolved. New York: W. W. Norton \& Company.

Boyer, P. (2008). Evolutionary economics of mental time travel? Trends in Cognitive Sciences $12(6), 219-224$.

Boyer, P. (2008). Religion explained. New York: Random House.

Boyer, P., \& Petersen, M. B. (2018). Folk-economic beliefs: An evolutionary cognitive model, Behavioral and Brain Sciences 41.

Buss, D. M. (2019). Evolutionary psychology: The new science of the mind. London: Routledge.

Buss, D. M. (2009). How can evolutionary psychology successfully explain personality and individual differences? Perspectives on Psychological Science 4(4), 359-366.

Churchill, S. E., Franciscus, R. G., McKean-Peraza, H. A., Daniel, J. A., \& Warren, B. R. (2009). Shanidar 3 Neandertal rib puncture wound and paleolithic weaponry, Journal of Human Evolution 57(2), 163-178. 
Clifford, S., \& Piston, S. (2017). Explaining public support for counterproductive homelessness policy: The role of disgust, Political Behavior 39(2), 503-525.

Clifford, S., \& Wendell, D. G. (2016). How disgust influences health purity attitudes, Political Behavior 38(1), 155-178.

Cochran, G., \& Harpending, H. (2009). The 10,000 year explosion: How civilization accelerated human evolution. New York: Basic Books.

Cosmides, L., \& Tooby, J. (1992). Cognitive adaptations for social exchange. In J. H. Barkow, L. Cosmides, \& J. Tooby (Eds.), The adapted mind: Evolutionary psychology and the generation of culture (pp. 163-228). Oxford: Oxford University Press.

Cosmides, L., \& Tooby, J. (2015). Adaptations for reasoning about social exchange. In D. M. Buss (Ed.), The handbook of evolutionary psychology, Volume 2 (625-668). Hoboken, NJ: John Wiley and Sons.

Crisp, R. J., \& Turner, R. N. (2009). Can imagined interactions produce positive perceptions?: Reducing prejudice through simulated social contact, American Psychologist 64(4), 231.

De Waal, F. B. (1996). Good natured: The origins of right and wrong in humans and other animals (No. 87). Cambridge, MA: Harvard University Press.

Doyen, S., Klein, O., Pichon, C. L., \& Cleeremans, A. (2012). Behavioral priming: It's all in the mind, but whose mind? PlOS One 7(1), e29081.

Faulkner, J., Schaller, M., Park, J. H., \& Duncan, L. A. (2004). Evolved disease-avoidance mechanisms and contemporary xenophobic attitudes, Group Processes \& Intergroup Relations 7(4), 333-353.

Gat, A. (2008). War in human civilization. Oxford: Oxford University Press.

Gilens, M. (1999). Why Americans hate welfare: Race, media, and the politics of antipoverty policy. Chicago: University of Chicago Press. 
Grubbs, J. B., Warmke, B., Tosi, J., James, A. S., \& Campbell, W. K. (2019). Moral grandstanding in public discourse: Status-seeking motives as a potential explanatory mechanism in predicting conflict, PlOS One 14(10), e0223749.

Hamilton, W. D. (1964). The genetical evolution of social behaviour. II, Journal of Theoretical Biology 7(1), 17-52.

Horowitz, D. L. (2001). The deadly ethnic riot. Berkeley, CA: University of California Press. Hublin, J. J. (2009). The prehistory of compassion, Proceedings of the National Academy of Sciences 106(16), 6429-6430.

Kahneman, D. (2011). Thinking, fast and slow. New York: Macmillan.

Kam, C. D. (2005). Who toes the party line? Cues, values, and individual differences, Political Behavior 27(2), 163-182.

Kaplan, H., Hill, K., Lancaster, J., \& Hurtado, A. M. (2000). A theory of human life history evolution: Diet, intelligence, and longevity, Evolutionary Anthropology: Issues, News, and Reviews: Issues, News, and Reviews 9(4), 156-185.

Karinen, A. K., Molho, C., Kupfer, T. R., \& Tybur, J. M. (2019). Disgust sensitivity and opposition to immigration: Does contact avoidance or resistance to foreign norms explain the relationship? Journal of Experimental Social Psychology 84, 103817.

Kelly, R. L. (2013). The lifeways of hunter-gatherers: the foraging spectrum. Cambridge: Cambridge University Press.

Kenrick, D. T., Griskevicius, V., Neuberg, S. L., \& Schaller, M. (2010). Renovating the pyramid of needs: Contemporary extensions built upon ancient foundations, Perspectives on Psychological Science 5(3), 292-314. 
Kerry, N., \& Murray, D. R. (2018). Conservative parenting: Investigating the relationships between parenthood, moral judgment, and social conservatism, Personality and Individual Differences $134,88-96$.

Klofstad, C. A., McDermott, R., \& Hatemi, P. K. (2012). Do bedroom eyes wear political glasses? The role of politics in human mate attraction, Evolution and Human Behavior 33(2), 100-108. Ksiazkiewicz, A. (2020). Conservative larks, liberal owls: The relationship between chronotype and political ideology, The Journal of Politics 82(1), 367-371.

Kurzban, R. (2011). Why everyone (else) is a hypocrite. Princeton, NJ: Princeton University Press. Kurzban, R., \& Athena Aktipis, C. (2007). Modularity and the social mind: Are psychologists too self-ish? Personality and Social Psychology Review 11(2), 131-149.

Kurzban, R., Tooby, J., \& Cosmides, L. (2001). Can race be erased? Coalitional computation and social categorization, Proceedings of the National Academy of Sciences 98(26), 1538715392.

Lakatos, I. (1976). Falsification and the methodology of scientific research programmes. In S. G. Harding (Ed.), Can theories be refuted? (pp. 205-259). Dordrecht: Springer.

Lasswell, H. D. (2018). Politics: Who gets what, when, how. Pickle Partners Publishing. Laustsen, L., \& Petersen, M. B. (2017). Perceived conflict and leader dominance: Individual and contextual factors behind preferences for dominant leaders, Political Psychology 38(6), 10831101.

Lieberman, D., Tooby, J., \& Cosmides, L. (2007). The architecture of human kin detection, Nature 445(7129), 727-731.

Lippmann, W. (1929). Public Opinion. New York: Macmillan Company.

Maner, J. K. (2017). Dominance and prestige: A tale of two hierarchies, Current Directions in Psychological Science 26(6), 526-531. 
Mermin, N. D. (2004). Could Feynman have said this, Physics Today 57(5), 10.

Nairne, J. S. (2014). Adaptive memory: Novel findings acquired through forward engineering. In Remembering (pp. 27-38). Psychology Press.

Navarrete, C. D., \& Fessler, D. M. (2006). Disease avoidance and ethnocentrism: The effects of disease vulnerability and disgust sensitivity on intergroup attitudes, Evolution and Human Behavior 27(4), 270-282.

Nosek, B. A., Spies, J. R., \& Motyl, M. (2012). Scientific utopia: II. Restructuring incentives and practices to promote truth over publishability, Perspectives on Psychological Science 7(6), $615-631$.

Oorschot, W. V. (2000). Who should get what, and why? On deservingness criteria and the conditionality of solidarity among the public, Policy \& Politics $28(1), 33-48$.

Osmundsen, M., Bor, A., Vahlstrup, P. B., Bechmann, A., \& Petersen, M. B. (2021). Partisan polarization is the primary psychological motivation behind "fake news" sharing on Twitter, American Political Science Review 115(3), 999-1015.

Ostrom, E., \& Walker, J. (Eds.). (2003). Trust and reciprocity: Interdisciplinary lessons for experimental research. New York: Russell Sage Foundation.

Penke, L., Denissen, J. J., \& Miller, G. F. (2007). The evolutionary genetics of personality, European Journal of Personality: Published for the European Association of Personality Psychology 21(5), 549-587.

Pennycook, G., \& Rand, D. G. (2019). Lazy, not biased: Susceptibility to partisan fake news is better explained by lack of reasoning than by motivated reasoning, Cognition 188, 39-50.

Pennycook, G., Epstein, Z., Mosleh, M., Arechar, A. A., Eckles, D., \& Rand, D. G. (2021). Shifting attention to accuracy can reduce misinformation online, Nature 592(7855), 590-595. 
Petersen, M. B. (2012). Social welfare as small-scale help: evolutionary psychology and the deservingness heuristic, American Journal of Political Science 56(1), 1-16.

Petersen, M. B. (2015). Evolutionary political psychology: On the origin and structure of heuristics and biases in politics, Political Psychology 36, 45-78.

Petersen, M. B. (2017). Healthy out-group members are represented psychologically as infected ingroup members, Psychological Science 28(12), 1857-1863.

Petersen, M. B. (2018). Reproductive interests and dimensions of political ideology, Evolution and Human Behavior 39(2), 203-211.

Petersen, M. B. (2020). The evolutionary psychology of mass mobilization: how disinformation and demagogues coordinate rather than manipulate, Current Opinion in Psychology 35, 71-75.

Petersen, M. B., \& Arceneaux, K. (2020). An Intuitionist Theory of Argument Strength in Politics: How Intuitive Cognitive Biases Produce Universally Strong Arguments, Political Psychology $41(6), 1113-1131$.

Petersen, M. B., \& Aarøe, L. (2012). Is the political animal politically ignorant? Applying evolutionary psychology to the study of political attitudes, Evolutionary Psychology 10(5), doi:10.1177/147470491201000504

Petersen, M. B., \& Aarøe, L. (2013). Politics in the mind's eye: Imagination as a link between social and political cognition, American Political Science Review 107(2), 275-293.

Petersen, M. B., Osmundsen, M., \& Arceneaux, K. (2018). A "need for chaos" and the sharing of hostile political rumors in advanced democracies, American Political Science Association, Boston, MA, August 30-September 2, 2018.

Petersen, M. B., Osmundsen, M., \& Bor, A. (2021). Beyond Populism: The Psychology of StatusSeeking and Extreme Political Discontent. In J. P. Forgas, W. D. Crano, \& K. Fiedler (Eds.), The Psychology of Populism (pp. 62-80). New York: Routledge. 
Petersen, M. B., Osmundsen, M., \& Tooby, J. (2020). The Evolutionary Psychology of Conflict and the Functions of Falsehood. doi: 10.31234/osf.io/kaby9

Petersen, M. B., Sell, A., Tooby, J., \& Cosmides, L. (2012). To punish or repair? Evolutionary psychology and lay intuitions about modern criminal justice, Evolution and Human Behavior $33(6), 682-695$.

Petersen, M. B., Slothuus, R., Stubager, R., \& Togeby, L. (2011). Deservingness versus values in public opinion on welfare: The automaticity of the deservingness heuristic, European Journal of Political Research 50(1), 24-52.

Petersen, M. B., Sznycer, D., Cosmides, L., \& Tooby, J. (2012). Who deserves help? Evolutionary psychology, social emotions, and public opinion about welfare, Political Psychology 33(3), $395-418$.

Pinker, S. (2003). How the Mind Works. London: Penguin UK.

Popper, K. (2005 [1959]). The logic of scientific discovery. London: Routledge.

Price, M. E., \& Van Vugt, M. (2014). The evolution of leader-follower reciprocity: the theory of service-for-prestige, Frontiers in Human Neuroscience 8, 363.

Quillien, T., \& German, T. C. (2021). A simple definition of 'intentionally,' Cognition 214. doi:

\section{$\underline{10.1016 / j . c o g n i t i o n .2021 .104806}$}

Rozin, P., Millman, L., \& Nemeroff, C. (1986). Operation of the laws of sympathetic magic in disgust and other domains, Journal of Personality and Social Psychology 50(4), 703.

Rubin, M., \& Hewstone, M. (1998). Social identity theory's self-esteem hypothesis: A review and some suggestions for clarification, Personality and Social Psychology Review 2(1), 40-62.

Ryan, S., Oaten, M., Stevenson, R. J., \& Case, T. I. (2012). Facial disfigurement is treated like an infectious disease, Evolution and Human Behavior 33(6), 639-646. 
Schaller, M., \& Park, J. H. (2011). The behavioral immune system (and why it matters), Current Directions in Psychological Science 20(2), 99-103.

Scott-Phillips, T. C., Dickins, T. E., \& West, S. A. (2011). Evolutionary theory and the ultimateproximate distinction in the human behavioral sciences, Perspectives on Psychological Science 6(1), 38-47.

Sell, A., Sznycer, D., Cosmides, L., Tooby, J., Krauss, A., Nisu, S., ... \& Petersen, M. B. (2017). Physically strong men are more militant: A test across four countries, Evolution and Human Behavior 38(3), 334-340.

Sell, A., Tooby, J., \& Cosmides, L. (2009). Formidability and the logic of human anger, Proceedings of the National Academy of Sciences 106(35), 15073-15078.

Sherlock, J. M., Zietsch, B. P., Tybur, J. M., \& Jern, P. (2016). The quantitative genetics of disgust sensitivity, Emotion 16(1), 43.

Skitka, L. J., \& Tetlock, P. E. (1993). Providing public assistance: Cognitive and motivational processes underlying liberal and conservative policy preferences, Journal of Personality and Social Psychology 65(6), 1205.

Smith, K. B., Alford, J. R., Hibbing, J. R., Martin, N. G., \& Hatemi, P. K. (2017). Intuitive ethics and political orientations: Testing moral foundations as a theory of political ideology, American Journal of Political Science 61(2), 424-437.

Sniderman, P. M., \& Bullock, J. (2018). A consistency theory of public opinion and political choice: The hypothesis of menu dependence. In W. E. Saris and P. M. Sniderman (Eds.), Studies in public opinion (pp. 337-358). Princeton, NJ: Princeton University Press.

Sniderman, P. M., Brody, R. A., \& Tetlock, P. E. (1993). Reasoning and choice: Explorations in political psychology. Cambridge: Cambridge University Press. 
Stone, V. E., Cosmides, L., Tooby, J., Kroll, N., \& Knight, R. T. (2002). Selective impairment of reasoning about social exchange in a patient with bilateral limbic system damage, Proceedings of the National Academy of Sciences 99(17), 11531-11536.

Sugiyama, L. S., Tooby, J., \& Cosmides, L. (2002). Cross-cultural evidence of cognitive adaptations for social exchange among the Shiwiar of Ecuadorian Amazonia, Proceedings of the National Academy of Sciences 99(17), 11537-11542.

Tanskanen, A. O., Danielsbacka, M., \& Rotkirch, A. (2021). Kin detection cues and sibling relationship quality in adulthood: The role of childhood co-residence duration and maternal perinatal association, Evolution and Human Behavior 42(6), 481-490.

Terrizzi Jr, J. A., Shook, N. J., \& Ventis, W. L. (2010). Disgust: A predictor of social conservatism and prejudicial attitudes toward homosexuals, Personality and Individual Differences 49(6), $587-592$.

Todd, P. M., \& Gigerenzer, G. (2007). Environments that make us smart: Ecological rationality, Current Directions in Psychological Science 16(3), 167-171.

Tomasello, M. (2014). The ultra-social animal, European Journal of Social Psychology 44(3), 187194.

Tooby, J. (1982). Pathogens, polymorphism, and the evolution of sex, Journal of Theoretical Biology 97(4), 557-576.

Tooby, J., \& Cosmides, L. (1990). The past explains the present: Emotional adaptations and the structure of ancestral environments, Ethology and Sociobiology 11(4-5), 375-424.

Tooby, J., \& Cosmides, L. (1992). The psychological foundations of culture. In J. H. Barkow, L. Cosmides, \& J. Tooby (Eds.), The adapted mind: Evolutionary psychology and the generation of culture (pp. 19-136). Oxford: Oxford University Press 
Tooby, J., Cosmides, L., \& Barrett, H. C. (2005). Resolving the debate on innate ideas. In P. Caruthers, S. Laurence, and S. Stitch (Eds.), The innate mind: Structure and content (pp. 305337). Oxford: Oxford University Press.

Tooby, J., Cosmides, L., \& Price, M. E. (2006). Cognitive adaptations for n-person exchange: The evolutionary roots of organizational behavior, Managerial and Decision Economics 27(2-3), $103-129$.

Trivers, R. L. (1971). The evolution of reciprocal altruism, The Quarterly Review of Biology 46(1), $35-57$.

Tybur, J. M., Inbar, Y., Aarøe, L., Barclay, P., Barlow, F. K., De Barra, M., ... \& Žeželj, I. (2016). Parasite stress and pathogen avoidance relate to distinct dimensions of political ideology across 30 nations, Proceedings of the National Academy of Sciences 113(44), 12408-12413.

van Leeuwen, F., \& Petersen, M. B. (2018). The behavioral immune system is designed to avoid infected individuals, not outgroups, Evolution and Human Behavior 39(2), 226-234.

Wilson, E. O. (2000). Consilience. New York: Alfred A Knopf.

Wright, R. (2017). Why Buddhism is true: The science and philosophy of meditation and enlightenment. New York: Simon and Schuster.

Wrangham, R. W., \& Glowacki, L. (2012). Intergroup aggression in chimpanzees and war in nomadic hunter-gatherers, Human Nature 23(1), 5-29. 